\title{
3 Research Square

\section{Antioxidant Hydrolysate Production From Bovine Collagen With Trypsin; Optimized by Response Surface Methodology}

\section{Babak Pakbin ( $\sim$ b.pakbin@ut.ac.ir)}

Qazvin University of Medical Sciences and University of Applied Sciences Western Switzerland ValaisWallis https://orcid.org/0000-0003-1412-0890

\section{Samaneh Allahyari}

Qazvin University of Medical Sciences

\section{Shaghayegh Pishkhan Dibazar}

Qazvin University of Medical Sciences

\section{Wolfram Manuel Brück}

HES-SO Valais Wallis

\section{Roghayeh Vahidi}

Qazvin University of Medical Sciences

\section{Razzagh Mahmoudi}

Qazvin University of Medical Sciences

\section{Research note}

Keywords: Bovine gelatin, Protein hydrolysate, Antioxidant activity, Trypsin, Response surface methodology

Posted Date: July 8th, 2021

DOI: https://doi.org/10.21203/rs.3.rs-690801/v1

License: (c) (1) This work is licensed under a Creative Commons Attribution 4.0 International License. Read Full License 


\section{Abstract}

Objective: Gelatin is a byproduct of meat industry and its hydrolysates showed several functionalities such as antioxidant activity. Response surface methodology (RSM) is a statistical method to mode and optimize biological processes. The purpose of this study was to describe and optimize the enzymatic hydrolysis conditions including time, temperature, $\mathrm{pH}$, and enzyme/substrate ratio $(\mathrm{E} / \mathrm{S})$ to produce protein hydrolysate with antioxidant functionality from bovine gelatin by RSM. The scavenging activity was also evaluated using the DPPH method.

Results: In this study, we developed and evaluated a model using RSM to describe and optimize conditions of enzymatic hydrolysis of bovine gelatin by trypsin to produce a protein hydrolysate with antioxidant activity. The model was observed and fitted with desirable adequacy and sufficiency. We found that the antioxidant activity increased significantly $(P<0.05)$ with increasing $\mathrm{pH}, \mathrm{E} / \mathrm{S}$ ratio and time of enzymatic process. However, temperature had no significant $(P<0.05)$ effect on the antioxidant activity of the hydrolysate. The optimum hydrolysis conditions were observed at the temperature 30-50 ${ }^{\circ} \mathrm{C}, \mathrm{pH} 8.0, \mathrm{E} / \mathrm{S}$ ratio at 2.5 after $2 \mathrm{~h}$ of trypsin hydrolysis. The results showed that the hydrolysate under these conditions had greater antioxidant activity.

\section{Introduction}

Collagen is the predominant structural protein in vertebrate and invertebrate animals and the principal fibrous protein constituent in skin, bone, and cartilage. Gelatin is a soluble protein derived from collagen and obtained by partial hydrolysis. Gelatin is widely used for its functional and nutritional properties in food and pharmaceutical industries. Currently, collagen is mainly extracted from the skin and bones of cows and pigs. Collagen and gelatin are the main proteinaceous byproducts of the meat industry. However, disposal and utilization of these byproducts can reduce the cost of production and generate income for producers (1). Gelatin derived peptides and hydrolysates showed several functional activities and potential biological benefits including antioxidant, anticancer, cholesterol lowering and antihypertensive effects. More than half of the amino acid residues in the collagen a-chain contain glycine, proline, and hydroxyproline amino acids. Presence of both proline and glycine amino acids are associated with radical scavenging and antioxidant activity of gelatin hydrolysate as a bioactive peptide (2).

Bioactive peptides(biopeptides) have been characterized as specific fragments of native proteins that have positive effects on human body conditions which eventually promote health and well-being. Several studies showed the biological functionalities of different biopeptides including antioxidant, immunomodulatory, antidiabetic, mineral binding, anti-thrombotic, opioid, antimicrobial and antihypertensive activities (3). Many food proteins such as bovine milk, dairy products, animal blood, different animal meats, egg, gelatin, and plant-based proteins obtained from rice, maize, soy, mushrooms, etc. were used as sources of biopeptide production. The three main biopeptide production methods are enzymatic hydrolysis, microbial fermentation, and chemical synthesis. Enzymatic digestion is the most 
reliable, productive, and efficient method to produce biopeptides with the highest antihypertensive and antioxidant activity. Antioxidants and biopeptides with antioxidant activity are used for removing free radicals and prevention of oxidation reactions in the food and drug industry (4). Various types of proteases such as trypsin, chymotrypsin and papain have been used for production of antioxidant biopeptides from food proteins (5). To be most effective and efficient, all enzymatic reactions are recommended to be performed under optimized conditions. There are four main parameters including time, temperature, $\mathrm{pH}$ and enzyme/substrate that cooperatively affect the enzyme efficiency and activity thereby making the bioprocess more productive and controllable (4). Response surface methodology (RSM) is a statistical method, which has been developed and frequently used to optimize the conditions of enzymatic reactions using all the variables simultaneously. RSM has been applied in several studies to design the experiments and optimize the enzymatic reactions for production of antioxidant biopeptides from food protein sources (6). However, there is no available data about the application of RSM to optimize the production of antioxidant biopeptides from bovine gelatin by enzymatic hydrolysis.

Therefore, the objective of this study was to optimize the enzymatic hydrolysis conditions including time, temperature, $\mathrm{pH}$, and enzyme/substrate ratio to produce biopeptides with antioxidant functionality from bovine gelatin by RSM.

\section{Main Text}

\section{Preparation of gelatin hydrolysate}

Bovine gelatin in powder form (Sigma, USA) as the substrate and trypsin (buffer, $0.1 \mathrm{M} \mathrm{Na}_{2} \mathrm{HPO}_{4}-$ $\mathrm{NaH}_{2} \mathrm{PO}_{4}$; temperature $37^{\circ} \mathrm{C}$; $\mathrm{pH} 8.8$ ) (Sigma, USA) for enzymatic hydrolysis were used in this study. All chemicals used were of analytical grade. For the preparation of a $1 \% \mathrm{w} / \mathrm{v}$ gelatin solution, $1 \mathrm{~g}$ of bovine gelatin powder was mixed with $100 \mathrm{~mL}$ phosphate buffered saline $(\mathrm{pH}=7.4)$, heated and stirred at $50^{\circ} \mathrm{C}$ for $2 \mathrm{~h}$. To inactivate any enzymatic activity, gelatin solutions were heated at $95^{\circ} \mathrm{C}$ for $15 \mathrm{~min}$ in a boiling water bath. For $\mathrm{pH}$ adjustment, hydrochloric acid ( $0.1 \mathrm{~mol} / \mathrm{L}$, Merck, Germany), sodium hydroxide (0.1 $\mathrm{mol} / \mathrm{L}$, Merck, Germany) were used. Gelatin solutions were prepared and incubated at various $\mathrm{pH}$ levels, enzyme/substrate ratios (E/S), temperatures and times as determined by RSM optimization and modeling approaches.

\section{Optimization and modeling of enzymatic hydrolysis process by response surface methodology}

Response surface methodology was used to model and optimize the hydrolysis conditions of bovine gelatin hydrolysis using trypsin. Optimization of four variables including temperature $\left(X_{1}=30,35,40,45\right.$ and $\left.50^{\circ} \mathrm{C}\right)$, pH level $\left(X_{2}=5,6,7,8\right.$ and 9$)$, $E / S\left(X_{3}=2,2.5,3,3.5\right.$ and 4$)$ and time $\left(X_{4}=1,2,3,4\right.$ and $\left.5 \mathrm{~h}\right)$ for the level of antioxidant activity $(Y)$ was carried out using the Design-Expert software package version 10.0.3.1 (Stat-Ease Inc., Minneapolis, USA). The experimental design is presented in Table 1. Each variable contained five distinct levels. In total, 30 runs were performed, using a central composite rotatable design (CCRD) to scrutinize the impacts of the independent variables. The response function (Y) 
was associated with the coded variables $(\mathrm{X} 1, \mathrm{X} 2, \mathrm{X} 3$ and $\mathrm{X} 4)$ by a second order polynomial equation using the least squares method and the results of experiments were fitted with the following equation:

$Y=\beta_{0}+\beta_{1} X_{1}+\beta_{2} X_{2}+\beta_{3} X_{3}+\beta_{4} X_{4}+\beta_{11} X_{1} X_{1}+\beta_{22} X_{2} X_{2}+\beta_{33} X_{3} X_{3}+\beta_{44} X_{4} X_{4}+\beta_{12} X_{1} X_{2}+\beta_{13} X_{1} X_{3}+\beta_{14} X_{1} X_{4}$ $+\beta_{23} X_{2} X_{3}+\beta_{24} X_{2} X_{4}+\beta_{34} X_{3} X_{4}$

where $Y$ represents the level of antioxidant activity response; $\beta_{0}$, is the offset term; $\beta_{1}, \beta_{2}, \beta_{3}, \beta_{4}$ are the linear effect terms; $\beta_{11}, \beta_{22}, \beta_{33}, \beta_{44}$ are the squared effects, $\beta_{12}, \beta_{13}, \beta_{14}, \beta_{23}, \beta_{24}, \beta_{34}$ are the interaction effects; and $X_{1}, X_{2}, X_{3}$ and $X_{4}$ are the variables. Analysis of variance (ANOVA) was regarded to evaluate the significance level $(P<0.05)$ of polynomial regression model terms for the response value. $\mathrm{R}^{2}$, adjusted and predicted $R^{2}$ values are determination coefficients analyzed by F-test. Adequacy of the regression model was assessed by calculation of adequate precision (ADP), coefficient of variance (CV), lack of fit and the PRESS values. Fitness of the model was improved by omitting the non-significant $(P>0.05)$ terms. The model was verified by comparing the response values from experimental design and the predicted responses from the fitted and optimized model.

\section{Antioxidant activity}

The antioxidant activity of the hydrolyzed gelatin solutions was measured using DPPH (1, 1-diphenyl-2picrylhidrazyl) assay. The DPPH method was carried out as previously described by Kedare and Singh (2011) (7). In the presence of antioxidant compounds, DPPH is able to accept a hydrogen atom or an electron from the antioxidant molecules contributing to reduction of DPPH radicals and producing a noncolor ethanol solution. A $60 \mu \mathrm{L}$ aliquot of hydrolyzed gelatin solution (or ethanol as the negative control) was mixed with $60 \mu \mathrm{L}$ of DPPH solution ( $60 \mu \mathrm{M}$; prepared in ethanol) for $10 \mathrm{~s}$ then was transferred into a quartz capillary tube. After 30 min incubation, the scavenging activity of the hydrolyzed gelatin solution on DPPH radicals were evaluated spectrophotometrically and the absorbance of the samples were measured at $517 \mathrm{~nm}$. The antioxidant activity of the samples was calculated by the following formula:

Antioxidant activity $(\%)=\left(A_{c}-A_{s} / A_{c}\right) \times 100$

Where $A_{c}$ and $A_{s}$ represent the absorbance values of control and sample, respectively.

\section{Results}

In this study, the mathematical model represents the antioxidant activity $(\mathrm{Y})$ of bovine gelatin hydrolyzed by trypsin enzyme as a function of independent variables including temperature $\left(X_{1}\right), \mathrm{pH}\left(\mathrm{X}_{2}\right), \mathrm{E} / \mathrm{S}$ ratio $\left(X_{3}\right)$ and time $\left(X_{4}\right)$ within the region under evaluation were presented by the following equation:

$Y^{0.5}=11.44-0.33 X_{1}-0.93 X_{2}-0.67 X_{3}-0.23 X_{4}+0.004 X_{1}^{2}+0.69 X_{2}^{2}+0.11 X_{3}^{2}+0.036 X_{4}^{2}$

All independent variables significantly $(P<0.05)$ affected the antioxidant activity level of the hydrolysate. Not significant $(P=0.986)$ lack of fitness was observed for the response. Regression coefficients 
including $R^{2}$, predicted and adjusted $R^{2}$ were observed for the model obtained in this study $0.92,0.84$ and 0.90 , respectively indicating a good regression model fitness. Adequate precision (ADP) value, indicating signal to noise ratio, was 20.71 for the antioxidant activity model; however, the CV value was observed $10.5 \%$. Also, the PRESS value was calculated 0.073 for the model. Studentized residuals plot and normal plot of residuals (Fig. 1A and B) also indicated the adequacy of fitness for the model. Consequently, the fitted interaction and quadratic equation developed at the present study was able to describe and significantly predict the relationships between the independent variables and the response value with desirable sufficiency and adequacy. The effect and interaction of temperature, $\mathrm{pH}, \mathrm{E} / \mathrm{S}$ ratio and time of the enzymatic reaction on antioxidant activity of gelatin hydrolysate are shown in response surface plots (Figs. 2A - D) when one variable remains constant. We found that the antioxidant activity of the gelatin hydrolysates significantly increased with the increases in $\mathrm{E} / \mathrm{S}$ ratio, $\mathrm{pH}$ level and time of the hydrolysis process by trypsin enzyme. However, temperature (ranged between 30 to $50^{\circ} \mathrm{C}$ ) did not significantly affected the antioxidant activity of gelatin hydrolysate in this study. The results of optimization indicated that the optimum antioxidant activity with the desirability of $85 \%$ was observed in the hydrolysis conditions including temperature $30-50^{\circ} \mathrm{C}, \mathrm{pH} 8.0, \mathrm{E} / \mathrm{S}$ ratio at 2.5 after $2 \mathrm{~h}$ hydrolysis of bovine gelatin using trypsin enzyme.

\section{Discussion}

We developed a fitted quadratic and interaction equation to model and predict the significant relationships between independent variables including temperature, $\mathrm{pH}$ value, $\mathrm{E} / \mathrm{S}$ ratio and time, and the response of antioxidant activity of the hydrolyzed gelatin by trypsin enzyme. We provided a regression model using the RSM method with desirable adequacy, sufficiency, and accuracy to describe and optimize the enzymatic process efficiently. We showed that the antioxidant activity was significantly increased with the increases in $\mathrm{pH}$ value, $\mathrm{E} / \mathrm{S}$ ratio and time of the process. Temperature had no significant impact on the antioxidant activity. An increase in antioxidant activity is commonly attributed to the conditions of hydrolysis process. Because of changes in the molecular characteristics of proteins such as increased molecular charge, decreased molecular weight and structural exposure of hydrophobic groups may lead to augmentation in antioxidant activity of gelatin hydrolysate (8).

The results achieved in this study are comparable with the findings of Naik et al. (2013). They found that optimum conditions for producing whey protein hydrolysate using trypsin and optimization using RSM were $\mathrm{pH} 7.3$, a $0.05 \mathrm{E} / \mathrm{S}$ ratio and $8 \mathrm{~h}$ of hydrolysis. The antioxidant activity in that study was increased with increasing $\mathrm{pH}, \mathrm{E} / \mathrm{S}$ and process time (9). Our findings also are close to the results obtained by Halim and Sarbon (2017). They optimized the hydrolysis conditions of eel protein to produce biopeptides with antioxidant activity using RMS and showed that increases in $\mathrm{pH}$ and $\mathrm{E} / \mathrm{S}$ ratio contributed to an increase in antioxidant activity (10). Several studies evaluated and optimized the enzymatic production of antioxidant protein hydrolysates by using RSM. Intiquilla et al. (2018) reported that the highest scavenging activity was found in Tarwi protein hydrolyzed by alcalase with an E/S ratio of $1.87 \%$ after $138 \mathrm{~min}$. They also found that releasing more peptides containing aromatic and hydrophobic amino 
acids could contribute to the higher antioxidant activity observed (11). According to Qiu et al. (2019), composition of hydrophobic amino acids such as glycine is pivotal in antioxidant activity mediated by peptides produced from hydrolysis of gelatin which is especially rich in this amino acid. They also found that hydrolysis of gelatin by using alcalase and trypsin enzymes is contributed to production of hydrolysates with higher scavenging activity. It is also showed that, specific hydrolysis activity of trypsin is higher at alkaline pH levels (12). Moreover, Naqash and Nazeer (2012) showed that the peptide containing glycine, alanine, and arginine which is produced through the hydrolysis of gelatin exhibited the antioxidant activity (13).

\section{Conclusions}

In this study, we developed a fitted and adequate model using RSM to describe and optimize conditions of enzymatic hydrolysis of bovine gelatin by trypsin to produce protein hydrolysate with antioxidant activity. We found that the antioxidant activity increased with the increases in $\mathrm{pH}$ value, E/S ratio, and process time. Temperature had no significant effect on the antioxidant activity. However, the overall optimum hydrolysis conditions were temperature at $30-50^{\circ} \mathrm{C}, \mathrm{pH}$ of $8.0, \mathrm{E} / \mathrm{S}$ ratio at 2.5 after $2 \mathrm{~h}$ hydrolysis by trypsin enzyme. Bovine gelatin, as a byproduct of meat industry, has the potential to produce antioxidant bioactive peptide.

\section{Limitation}

- DPPH method is not only sufficient to evaluate the antioxidant and scavenging activity of the protein hydrolysate. However, other evaluations such as degree of hydrolysis is recommended to be performed in this type of study.

\section{Abbreviations}

RSM: Response Surface Methodology; E/S: Enzyme Substrate; CCRD: Central Composite Rotatable Design; ADP: Adequate Precision; CV: Coefficient of Variance; DPPH: 1, 1-diphenyl-2-picrylhidrazyl.

\section{Declarations}

\section{Ethics approval and consent to participate}

Not applicable.

\section{Consent for publication}

Not applicable.

\section{Availability of data and materials}

All data are available from the corresponding author on a reasonable request. 


\section{Competing interests}

The authors declare that they have no competing interest.

\section{Funding}

This research was self-funded.

\section{Authors' contributions}

BP designed the research; BP and RV performed all experiments; RM supervised the project; BP, SA and SPD performed all analysis; BP and WMB wrote the first draft; WMB reviewed and finalized the manuscript; All authors approved the final version of the manuscript.

\section{Acknowledgements}

We greatly thank and appreciate all experimental technicians in Qazvin University of Medical Science.

\section{References}

1. Liu D, Nikoo M, Boran G, Zhou P, Regenstein JM. Collagen and gelatin. Annual review of food science and technology. 2015;6:527-57.

2. Gómez-Guillén $M$, Giménez $B$, López-Caballero Ma, Montero M. Functional and bioactive properties of collagen and gelatin from alternative sources: A review. Food hydrocolloids. 2011;25(8):1813-27.

3. Daliri EB-M, Oh DH, Lee BH. Bioactive peptides. Foods. 2017;6(5):32.

4. Lorenzo JM, Munekata PE, Gomez B, Barba FJ, Mora L, Perez-Santaescolastica C, et al. Bioactive peptides as natural antioxidants in food products-A review. Trends in food science \& technology. 2018;79:136-47.

5. Chakrabarti S, Guha S, Majumder K. Food-derived bioactive peptides in human health: Challenges and opportunities. Nutrients. 2018;10(11):1738.

6. Yolmeh M, Jafari SM. Applications of response surface methodology in the food industry processes. Food and Bioprocess Technology. 2017;10(3):413-33.

7. Kedare SB, Singh R. Genesis and development of DPPH method of antioxidant assay. Journal of food science and technology. 2011;48(4):412-22.

8. Yang X-R, Qiu Y-T, Zhao Y-Q, Chi C-F, Wang B. Purification and characterization of antioxidant peptides derived from protein hydrolysate of the marine bivalve mollusk Tergillarca granosa. Marine drugs. 2019;17(5):251.

9. Naik L, Mann B, Bajaj R, Sangwan R, Sharma R. Process optimization for the production of biofunctional whey protein hydrolysates: adopting response surface methodology. International Journal of Peptide Research and Therapeutics. 2013;19(3):231-7. 
10. Halim NRA, Sarbon NM. A response surface approach on hydrolysis condition of eel (Monopterus Sp.) protein hydrolysate with antioxidant activity. International Food Research Journal. 2017;24(3).

11. Intiquilla A, Jiménez-Aliaga K, Zavaleta Al, Hernández-Ledesma B. Production of antioxidant hydrolyzates from a Lupinus mutabilis (Tarwi) protein concentrate with alcalase: Optimization by response surface methodology. Natural Product Communications. 2018;13(6):1934578X1801300626.

12. Qiu Y-T, Wang Y-M, Yang X-R, Zhao Y-Q, Chi C-F, Wang B. Gelatin and antioxidant peptides from gelatin hydrolysate of skipjack tuna (Katsuwonus pelamis) scales: Preparation, identification and activity evaluation. Marine drugs. 2019;17(10):565.

13. Naqash SY, Nazeer R. Optimization of enzymatic hydrolysis conditions for the production of antioxidant peptides from muscles of Nemipterus japonicus and Exocoetus volitans using response surface methodology. Amino Acids. 2012;43(1):337-45.

\section{Table}


Table 1

Experimental design to optimize antioxidant activity of trypsin hydrolysis of bovine gelatin under various hydrolysis conditions

\begin{tabular}{|c|c|c|c|c|c|}
\hline Run no. & Temperature $\left({ }^{\circ} \mathrm{C}\right)$ & $\mathrm{pH}$ & $E / S^{a}$ & Time (h) & Antioxidant activity (\%) \\
\hline 1 & 45 & 8 & 2.5 & 4 & 15.1 \\
\hline 2 & 45 & 6 & 3.5 & 4 & 18.5 \\
\hline 3 & 40 & 9 & 3 & 3 & 31.3 \\
\hline 4 & 40 & 7 & 3 & 3 & 3.9 \\
\hline 5 & 35 & 8 & 2.5 & 4 & 22.6 \\
\hline 6 & 30 & 7 & 3 & 3 & 41.5 \\
\hline 7 & 45 & 8 & 3.5 & 4 & 18.3 \\
\hline 8 & 35 & 8 & 3.5 & 4 & 18.6 \\
\hline 9 & 40 & 7 & 3 & 3 & 3.3 \\
\hline 10 & 40 & 7 & 3 & 1 & 14.7 \\
\hline 11 & 50 & 7 & 3 & 3 & 30.4 \\
\hline 12 & 40 & 7 & 3 & 3 & 3.1 \\
\hline 13 & 45 & 6 & 3.5 & 2 & 12.4 \\
\hline 14 & 40 & 7 & 4 & 3 & 8.6 \\
\hline 15 & 35 & 6 & 2.5 & 2 & 18.7 \\
\hline 16 & 35 & 8 & 3.5 & 2 & 22.2 \\
\hline 17 & 40 & 5 & 3 & 3 & 13.3 \\
\hline 18 & 45 & 6 & 2.5 & 4 & 13.5 \\
\hline 19 & 40 & 7 & 3 & 3 & 3.6 \\
\hline 20 & 40 & 7 & 3 & 3 & 3.3 \\
\hline 21 & 35 & 6 & 3.5 & 4 & 14.9 \\
\hline 22 & 35 & 8 & 2.5 & 2 & 17.9 \\
\hline 23 & 35 & 6 & 2.5 & 4 & 13.5 \\
\hline 24 & 35 & 6 & 3.5 & 2 & 26.7 \\
\hline 25 & 40 & 7 & 2 & 3 & 9.6 \\
\hline 26 & 40 & 7 & 3 & 3 & 3.5 \\
\hline
\end{tabular}




\begin{tabular}{|llllll|}
27 & 45 & 8 & 3.5 & 2 & 28.6 \\
28 & 45 & 6 & 2.5 & 2 & 11.3 \\
29 & 45 & 8 & 2.5 & 2 & 18.9 \\
30 & 40 & 7 & 3 & 5 & 7.6 \\
\hline
\end{tabular}

${ }^{a} E / S$ : Enzyme subtrate ratio

Figures 


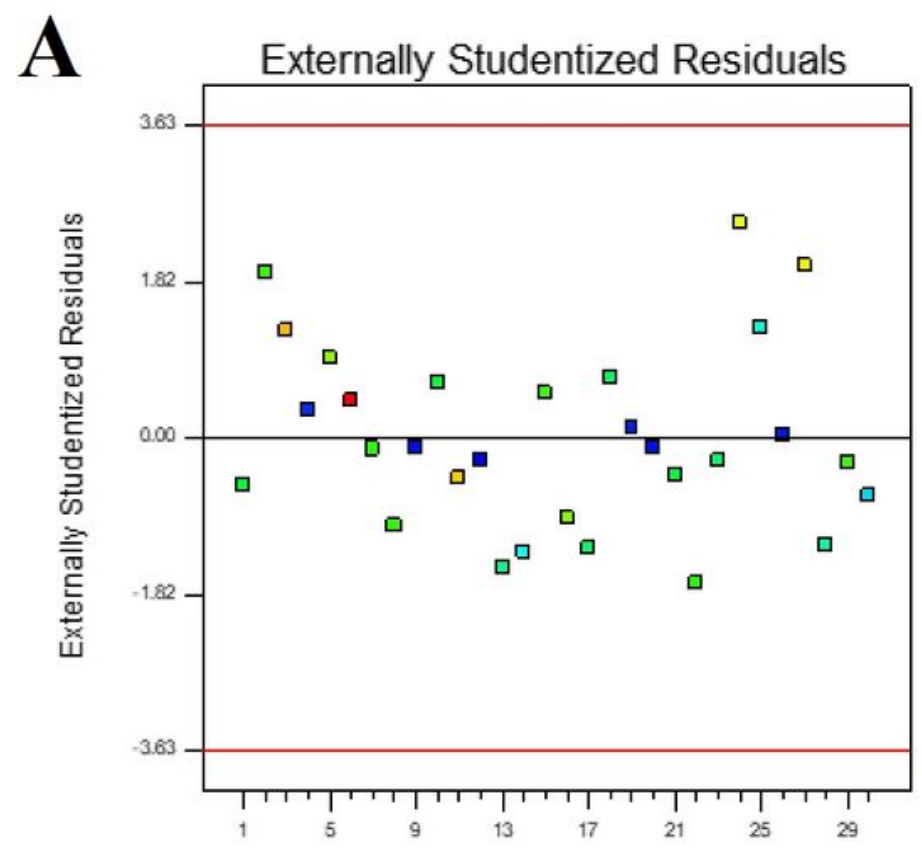

Run Number

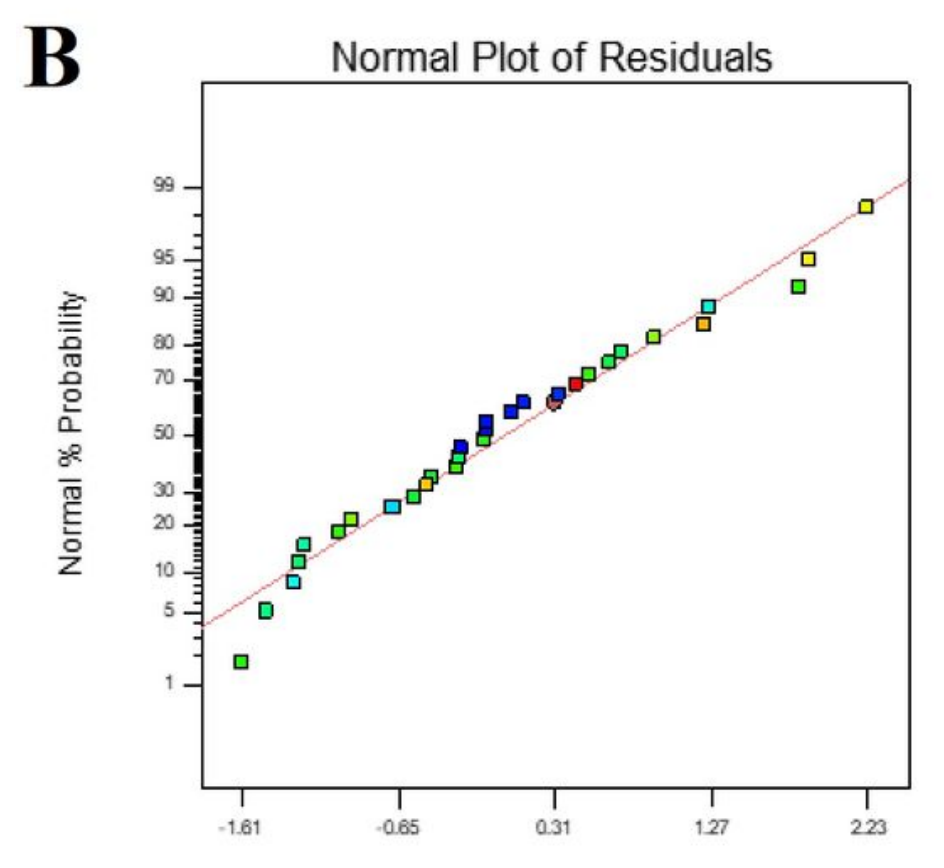

Internally Studentized Residuals

\section{Figure 1}

Studentized residuals plot and normal plot of residuals also indicated the adequacy of fitness for the model. 

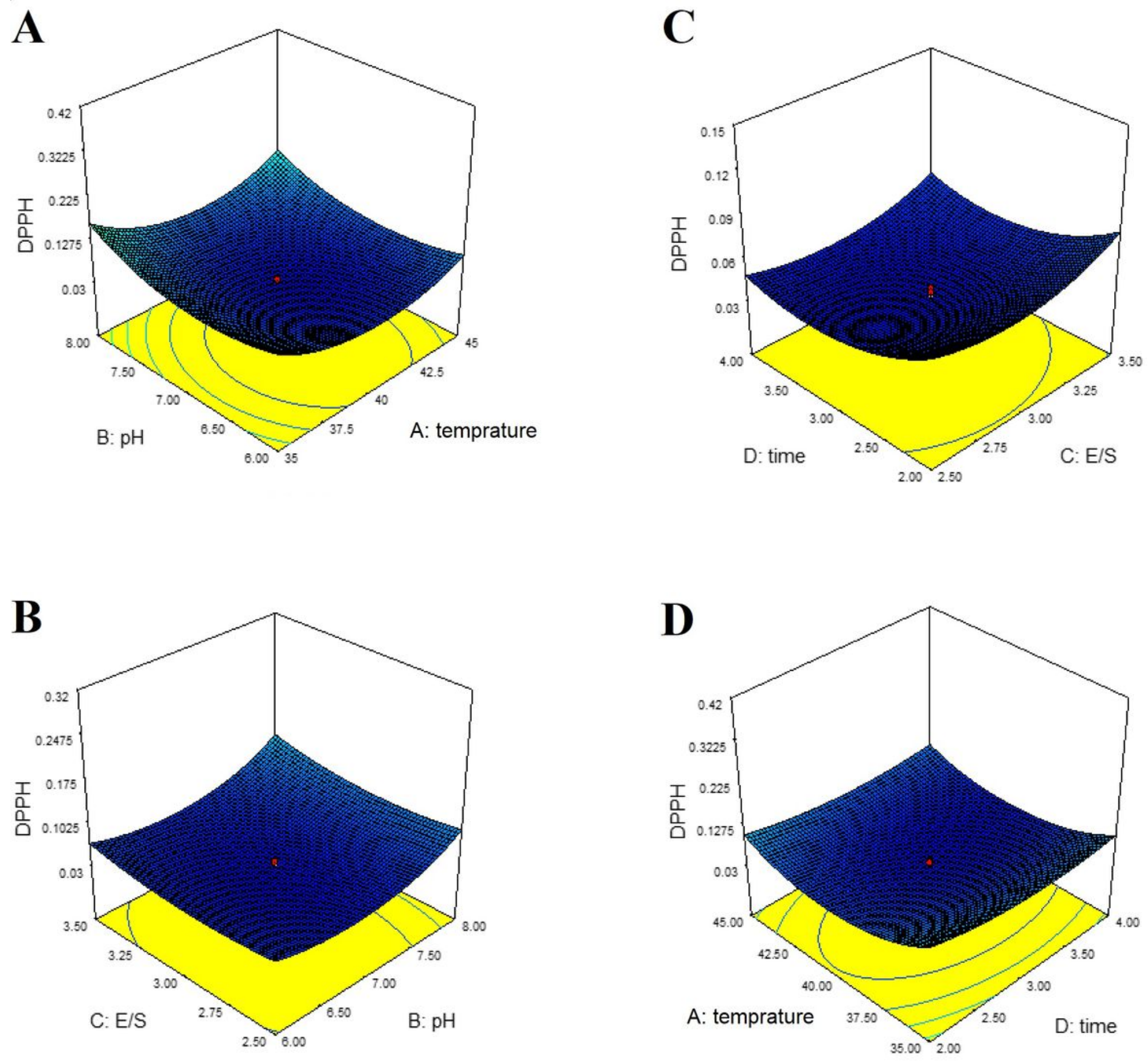

\section{Figure 2}

The effect and interaction of temperature, $\mathrm{pH}, \mathrm{E} / \mathrm{S}$ ratio and time of the enzymatic reaction on antioxidant activity of gelatin hydrolysate are shown in response surface plots when one variable remains constant. 